\title{
Liposuction: A Three Decade Experience
}

\section{Alaa Gheita*}

Department of Plastic Surgery, Faculty of Medicine, Cairo University, Kasr El Einy Hospital, 12 Hassan Sabry Street, Zamalek, Cairo, Egypt

*Corresponding author: Alaa Gheita, MD, Department of Plastic Surgery, Faculty of Medicine, Cairo University, Kasr El Einy Hospital, 12 Hassan Sabry Street, Zamalek, Cairo, Egypt, Tel: +201223132053; E-mail: Gheita@link.net

Received date: May 27, 2014, Accepted date: April 2, 2015, Published date: April 5, 2015

Copyright: (C) 2015 Gheita A. This is an open-access article distributed under the terms of the Creative Commons Attribution License, which permits unrestricted use, distribution, and reproduction in any medium, provided the original author and source are credited.

\section{Short Communication}

As a result of men and women becoming increasingly conscious of their body's figure and shape, Liposuction and Liposculpture have become one of the most common procedures performed in aesthetic surgery today.

The distribution of fat in the human body has, for centuries, played an important role in the element of attraction towards the opposite sex, and although the concept of the ideal body has been dynamic for just as long, body fat distribution has always been a key factor.

When one considers the evolution of Aesthetic Surgery through time, it is clear that the introduction of the Liposuction procedure was a break through that allowed skilled surgeons to, with relative ease, drastically increase the sexual appeal of their patients.

Although one can trace the origins of the concept of Liposuction back to the 1920's, it was only really in the early seventies, around 1974 , that the procedure began to gain traction, with the father and son surgeon team of Arpad and Giorgio Fischer developed the, at the time, revolutionary techniques of blunt tunneling in Rome, Italy. It is from their innovative work that the art of modern Liposuction can draw its roots [1].

It was soon after the Fischers' success that the Parisian Dr. Pierre Fournier, notably developing the technique of syringe liposuction [2].

It was definitely Yves Gerard Illouz of France also in Paris in June 1977 who popularized liposuction with a cannula and a pump.

Illouz also brought to liposuction the use of hydrotomy, injecting saline at high speeds to the site of the localized fat deposits in order to soften the tissue and facilitate its suction from the area $[3,4]$.

Following the publication of his paper on his method, Illouz became the topic of great debate amongst plastic surgeons in Paris, and indeed internationally. Some resented the procedure and rejected it in its entirety, considering it to not be "real aesthetic surgery". However, the popularity of the procedure grew rapidly, and discussions as to its presence in the world of aesthetics were becoming more and more frequent in Paris at the time [3,4].

After much controversy, Illouz's new discovery was finally accepted at both a local and an international stage, and became the central theme of various plastic surgery conferences around the world. It is today accepted that the Illouz Method was a milestone in the history of aesthetic surgery.

Around 1982, we began to perform liposuction procedures in Paris and Cairo using a rotary pump and a blunt edge cannula. Some surgeons at that time were unsure as to whether it was best to use a sharp or blunt edged cannula and as a result of this, several debates ensued. At that time, it was our belief that a blunt cannula must be used in order to avulse the small vessels in the surrounding tissue, and avoid the complication of the formation of a large haemotoma [5].

Over the years, the openings of the cannulae used in practice have evolved from having one single opening to multiple parallel ones, in order to facilitate the passage of viscous lipids. Today, most surgeons will use a set of cannulae of different size, with anywhere from three to five openings, the choice of which will depend on the site of the fat being sucked. This provides a significant increase in the flow of fat through the pipes and a reduced overall procedure time, as compared to the old, single-opening cannula.

We prefer to use a dry liposuction method, as it has been shown to be more precise, leads to an accurate estimation of the removed and residual fat deposits (and their distribution), leads to better symmetry and produces minimal waves (if any). All this while also reducing the amount of time spent in the operating room.

Blood replacement was very infrequent in our practice, and only ever necessary if the volume of fat extracted exceeded roughly four liters, although this obviously varied from patient to patient.

Most parts of the human body have been subjected to fat removal, from the face down to the ankles. The aim of Liposculpture is, in essence, to harmonize the body silhouette and obtain an attractive look. Through the years, there have been specific sites found which give consistently favourable results. One of these spots, I have found to be the neck, mostly the submental region, where spectacular aesthetic results could be achieved with as little as $20 \mathrm{ccs}$ of aspirated fat, a fine 2 $\mathrm{mm}$ cannula and a skilled practitioner.

The most common site the riding breech deformities gave most of the time very good results, but caution should be observed in order to avoid over enthusiastic fat suction, which can result in an unsightly depression and waving of the skin, which came to us occasionally, especially after tumescent techniques. Another highly recommended and overlooked site for vast improvement was the medial aspect of the knee and ankle regions [6].

However, with that said, there are two sites which need special care and attention from the surgeon. The first of these regions is the scapular region of the back. One should be wary of liposuction on this area, as fat deposits are very tough, being fibro fatty, and do not come up easily in some patients, thus resulting in a disappointing outcome [7].

The other area where caution should be exercised is also a common area for liposuction, the abdomen. Fat here could recur if the patient does not respect a healthy lifestyle and doesn't avoid over eating. However, liposuction can and has been used with abdominal dermolipectomy as an adjunctive procedure with a very fine and long lasting outcome. The possibility of regaining fat, and possibly consulting with a dietician, should be discussed with the patient before 
Page 2 of 2

the decision is made, and after the surgery and recovery period, as many patients will simply fall back into old habits and simply be back in the clinic within a year, disappointed with their results asking for a repeat procedure, as a result of their own actions [8].

Liposuction on the whole has proved to be a very safe procedure if done properly without any serious complication. In my experience, the worst complications were seen after the laser liposuction and ultrasound where subcutaneous abscesses have formed and cutaneous ischemic changes have occurred, as a result of under skilled practitioners using the technology as a quick alternative to surgery, with little knowledge of the method of application, advertising a noninvasive procedure at the cost of the patient's well-being, normally with patients who are uninformed of the risks $[9,10]$.

These complications some were very serious, disfiguring and usually extremely difficult to remedy nearly impossible for a very simple or minor aesthetic procedure which by simple methods nearly always gave very favorable and excellent results and mostly, and most important of all, a highly satisfied patient.

\section{References}

1. Fischer G (1991) History of my procedure, the harpstring technique and the sterile fat safety box. In Fournier PF (ed) Liposculpture: the syringe technique. Arnette, Paris 9-21
2. Fischer A and Fischer G (1977) Revised technique for cellulitis fat reduction in riding breech deformity. Bull Int Acad Cosm Surg 2: 40-43.

3. Illouz YG (1984) The future of the reuse of the fat after liposuction. Aesthetic Surgery Journal of French Language 9: 36.

4. Illouz YG, DeVillers YT (1989) Body sculpturing by lipoplasty. Edinburgh, Churchill Livingstone.

5. Field LM (1987) The dermatologist and liposuction--a history. J Dermatol Surg Oncol 13: 1040-1041.

6. Klein J (1987) Tumescent technique. Am J Cosm Surg 4: 263-267.

7. Courtiss EH (1985) Suction lipectomy of the neck. Plast Reconstr Surg 76: $882-889$.

8. Lillis PJ (1988) Liposuction surgery under local anesthesia: limited blood loss and minimal lidocaine absorption. J Dermatol Surg Oncol 14: 1145-1148.

9. Aiache AE (1989) Surgical treatment of gynecomastia in the body builder. Plast Reconstr Surg 83: 61-66.

10. Gheita A (2008) Gynecomastia: the horizontal ellipse method for its correction. Aesthetic Plast Surg 32: 795-801. 